\title{
Shuttle Derived In-Line Heavy Lift Vehicle
}

\author{
Terry Greenwood. \\ NASA MSFC, Huntsville, Alabama, 35812 \\ Wallace Twichell ${ }^{\S}$ and Daniel Ferrari ${ }^{\dagger}$ \\ Lockheed Martin Space Systems, Michoud Operations, New Orleans, LA, 70189-0304 \\ and \\ Frederick Kuck ${ }^{\ddagger}$ \\ Boeing - Rocketdyne, Canoga Park, CA, $91309-7922$
}

This paper introduces an evolvable Space Shuttle derived family of launch vehicles. It details the steps in the evolution of the vehicle family, noting how the evolving lift capability compares with the evolving lift requirements. A system description is given for each vehicle. The cost of each development stage is described. Also discussed are demonstration programs, the merits of the SSME vs. an expendable rocket engine (RS-68), and finally, the next steps needed to refine this concept.

\section{Nomenclature}

$\begin{array}{ll}\text { SSME } & =\text { Space Shuttle Main Engine } \\ S S P & =\text { Space Shuttle Program } \\ m t & =\text { metric tons } \\ C E V & =\text { Crew Exploration Vehicle } \\ H L L V & =\text { Heavy Lift Launch Vehicle } \\ K l b & =\text { thousands of pounds } \\ M P T A & =\text { Main Propulsion Test Article } \\ S R B & =\text { Solid Rocket Booster } \\ M P S & =\text { Main Propulsion System } \\ A P U & =\text { Auxiliary Power Unit } \\ i s p & =\text { specific impulse. }\end{array}$

\section{Introduction}

Tn response to President Bush's Space Exploration Vision, both NASA and the aerospace industry have proposed Ivarious exploration architectures. The launch vehicles are a key element of these architectures. While some architectures are geared to exploit existing launch vehicles, many require the development of new vehicles to support manned flights and heavy lift. Three principle approaches are the "clean sheet" vehicle, further evolving the evolved expendable vehicles (Atlas V, Delta IV), or a new vehicle based on existing Shuttle elements and technology. In this paper we will present a concept for a family of Shuttle derived vehicles that satisfies initial crew delivery requirements and evolves to support "Mars and beyond" heavy lift requirements.

The ideal launch vehicle development scenario for supporting the Exploration Vision would be one in which the initial vehicle used to transport crew could evolve into the heavy lift launch vehicle needed to support Lunar and Mars missions. This "One Vehicle" concept would greatly reduce overall launch vehicle development costs. If the end point of such an evolutionary path is a vehicle with $100+$ metric ton lift capability, what would be the initial point on this evolutionary path? The concept begins with an In-Line Core Stage derived from the SSP External Tank used to launch the Crew Exploration Vehicle (CEV). This core stage would be the basis for a future $100+\mathrm{mt}$ launch

\footnotetext{
*Future Plans Manager, External Tank Project Office, EP31

${ }^{\dagger}$ Director, Business Development, PO Box 29304

${ }^{\S}$ Manager, Business Development, PO Box 29304

${ }^{\ddagger}$ Manager, SSME Advanced Projects, 6633 Canoga Ave./AB66
} 
vehicle. This paper discusses the system configuration of the Heavy Lift Vehicle in each of its evolutionary steps. It shows the relationship of the lift capability to the evolving lift requirements and discusses the cost impacts of adding the appropriate element at each step.

The issues associated with engine selection are examined. In particular, the RS-68 and SSME engines are compared. The impact to performance, reliability and cost for each is discussed. Each of these engines has significant differences in performance and cost that impact the vehicle design and affordability. The reliability enhancement of "engine out" capability is examined for each and the impacts in cost and performance addressed.

Much of the analyses and design efforts leading to the conclusions presented are preliminary. The tasks recommended to verify these conclusions are discussed. These include refinement of the preliminary analysis on the In-Line Core Stage as a CEV launch vehicle in order to verify the technical feasibility of this concept. Also discussed is the determination of the time phased funding requirements of this process to determine if this evolutionary concept will in fact produce a funding requirement "wedge" that will fit into the funding availability "wedge".

\section{Evolutionary Steps to Heavy Lift Capability}

The concept of an evolvable vehicle based on elements of the Space Shuttle parallels the Exploration Vision's concept for spiral development. NASA has laid out five spirals for the journey to Mars. They begin with the development of the CEV in Spiral 1 continue with Lunar Missions in Spirals 2 and 3 and culminate with the human missions to Mars in Spirals 4 and 5.
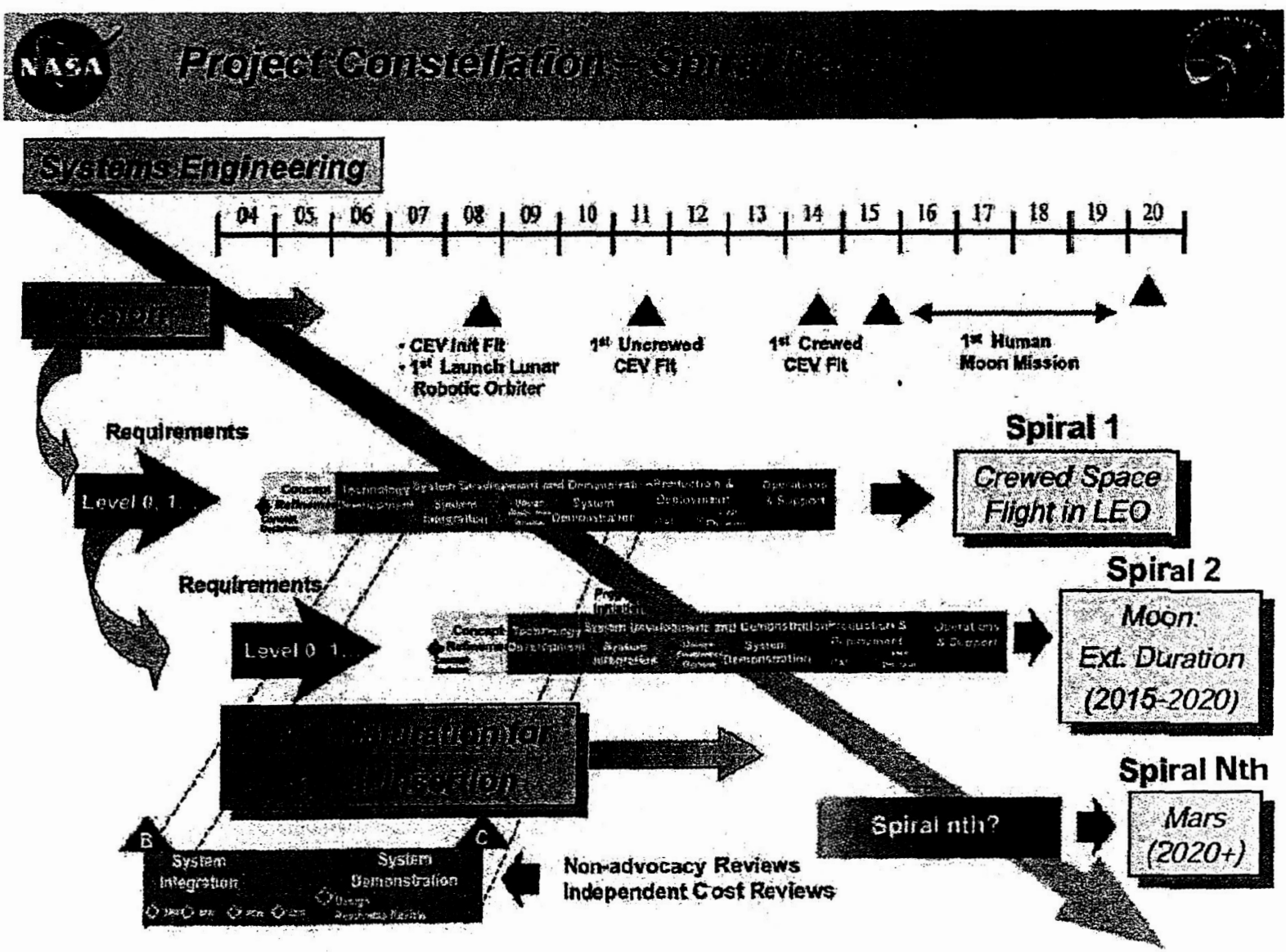

Figure 1. NASA's Spiral Develop Approach for The Exploration Vision (Project Constellation) ${ }^{1}$

The launch vehicle evolves from the initial capability to launch the CEV to a heavy lift vehicle for Earth to Orbit transport of Lunar cargo elements to an ultra-heavy lift vehicle for Earth to Orbit transport of cargo elements bound 
for Mars. Figure 2 shows this evolution, beginning with early ground based test articles to the Mars ultra-heavy lift launch vehicle.

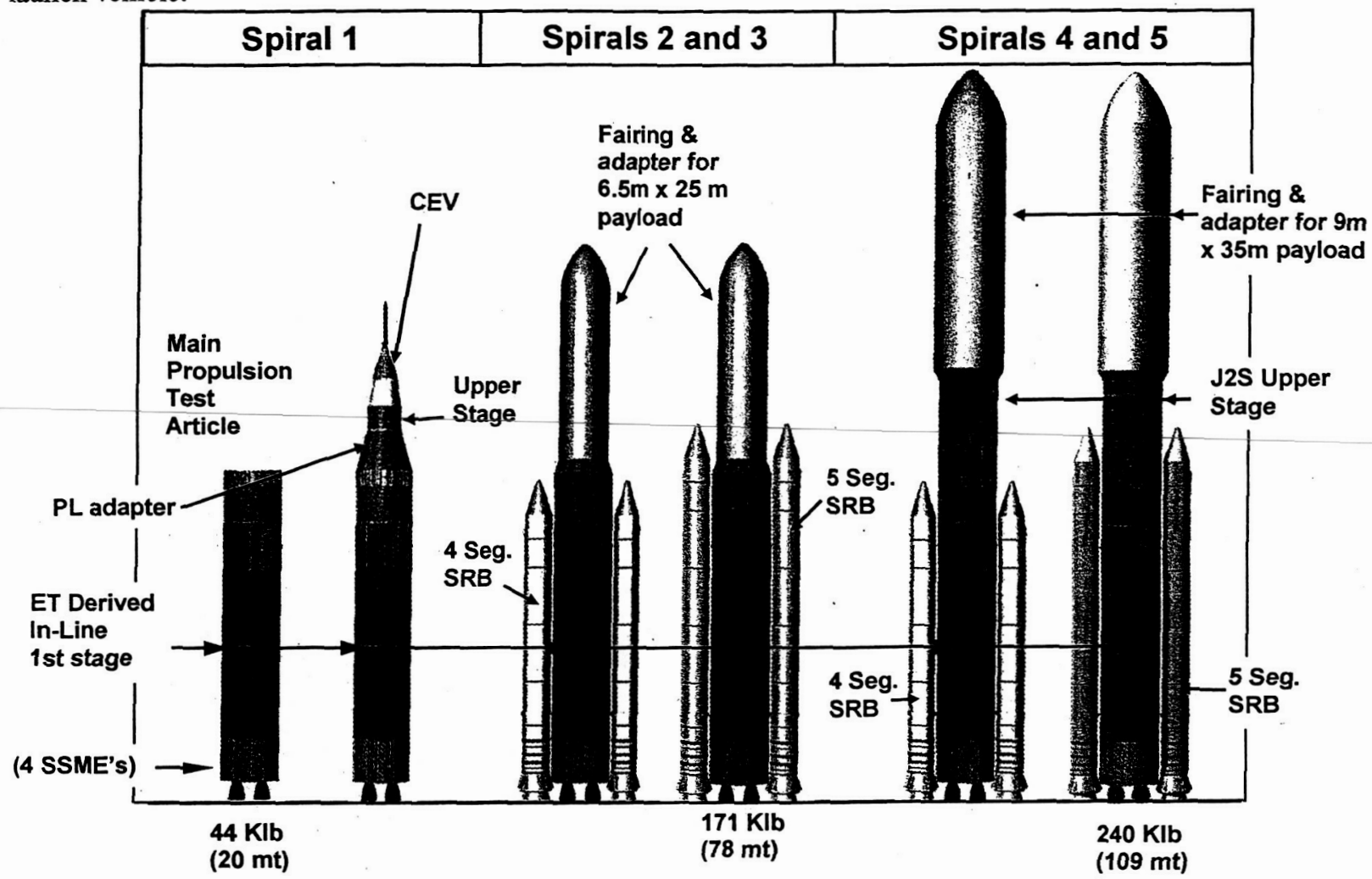

Figure 2. Launch Vehicle Evolutionary path matched to NASA's Project Constellation Development Spirals

The key element is the core stage of the vehicle which is developed for a first use as a main propulsion test article. This initial core stage is designed and tested using all of the requirements for each step in the evolution. This minimizes the development costs for each subsequent step of the evolution. The Steps in the evolution of the proposed family of vehicles are described in Table 1.

Table 1. Configuration Changes along the Evolutionary Steps

\begin{tabular}{|l|l|l|}
\hline \multicolumn{1}{|c|}{ Evolutionary Step } & \multicolumn{1}{|c|}{ Configuration } & \multicolumn{1}{|c|}{ Developments required for this Step } \\
\hline Step 1: MPTA & $\begin{array}{l}\text {-ET derived core stage without Cross Beam and } \\
\text { Thrust Panels in Intertank, including 4 SSME's }\end{array}$ & $\begin{array}{l}\text { Core Stage Development } \\
\text { - Tankage and Structure } \\
\text { - MPS, Avionics, APU's, RCS }\end{array}$ \\
\hline Step 2: CEV Launch Vehicle & $\begin{array}{l}\text { - ET derived core stage with 4 SSME's } \\
\text { - Upper Stage }\end{array}$ & Upper Stage \\
\hline Step 3: 70 mt Class HLLV & $\begin{array}{l}\text {-ET derived Core Stage with 4 SSME's } \\
\text { - Four Segment SRB's } \\
-6.5 \mathrm{~m} \text { X 25m Payload Fairing }\end{array}$ & $\begin{array}{l}\text { 6.5m X 25m Payload Fairing with } \\
\text { payload to core stage adapter }\end{array}$ \\
\hline Step 4: 80 mt Class HLLV & $\begin{array}{l}\text {-ET derived Core Stage with 4 SSME's } \\
\text {-Five Segment SRB's } \\
-6.5 \mathrm{~m} \text { X 25m Payload Fairing }\end{array}$ & Five Segment SRB \\
\hline Step 5: 100 mt Class HLLV & $\begin{array}{l}\text {-ET derived Core Stage with 4 SSME's } \\
\text {-Five Segment SRB's } \\
-9 \mathrm{mX} \text { 35m Payload Fairing } \\
- \text { Upper Stage }\end{array}$ & $\begin{array}{l}\text { Modify Upper Stage for additional } \\
\text { propellant. } \\
\text { Modify Payload Fairing for larger } \\
\text { payload volume. }\end{array}$ \\
\hline
\end{tabular}




\section{System Descriptions}

This family of vehicles is assembled from the subsystems and components of the Space Shuttle. These have a complete data base of cost, reliability and design information in existence. This significantly shortens the development process. In addition, these systems and components are currently man rated and are directly applicable for the first flight use of this family of vehicles.

\section{A. CEV Launch Vehicle}

The primary component of the CEV launch vehicle is the core stage. This stage provides the majority of the velocity to get to low earth orbit. This core stage will be developed using the components and manufacturing processes now used to build the Space Shuttle External Tank (ET). Figure 3 shows the ET heritage of the core stage.

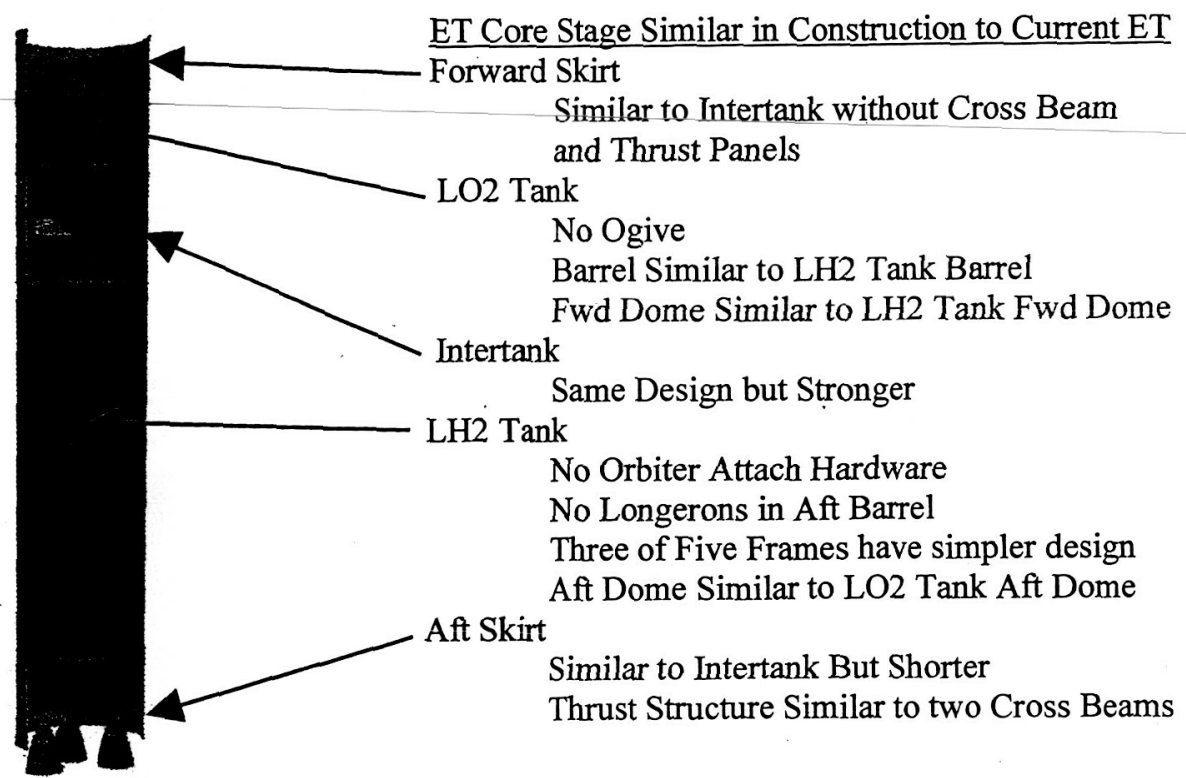
Figure 3. Designs, Processes, Facilities, Tooling and Flight Hardware are In Place to
build this Vehicle

The core fuel tank is a minimally modified Shuttle LH2 tank in which the shuttle attach fittings are deleted and the tank panels sized to take the additional thrust loads. The intertank would delete the cross beam and thrust panels, replacing them with skin and hat stringer panels. The forward LOX tank would have the same capacity of the current design, but with the ogive section replaced by an ET LH2 forward dome and the barrel section replaced with two modified barrels, to take the axial loads. This stage will be designed for the heavy lift loads, for commonality for each Step in the Evolution.

The Aft Skirt includes the engines, main propulsion system, thrust structure, and APU's. The main engines are currently base lined as unmodified Space Shuttle Main Engines; options for when the existing stock of SSME's have run out are Block II SSME's or a re-designed expendable SSME (E-SSME). . The MPS is derived from the Space Shuttle MPS, with simplifications for non-reusability. The Auxiliary Power units for hydraulics are derived from the H-APU's used in the SRB's.

The final velocity increment is provided by a relatively small upper stage. The sizing for this upper stage is shown in Figure 4. Given the performance of the core stage, the performance of the upper stage versus payload mass to a $220 \mathrm{~nm}$ by $28.5^{\circ}$ orbit was calculated. This was expressed in terms of velocity change provided by the upper stage. This was calculated assuming two different isp's, therefore there are two curves. An isp of 440 seconds corresponds to a LOX/Hydrogen engine and an isp of 280 seconds corresponds to an engine using. storable propellants. As shown in Figure 4, the best solution for a CEV weighing $20 \mathrm{mt}$ was determined a LOX/Hydrogen upper stage providing a delta velocity of 5000 feet per second. Guidance navigation and control (avionics) are EELV Derived, in order to minimized development and cost. The current avionics equipment used on the Space 
Shuttle is no longer in production and suffers obsolescence issues. This leads to the conclusion that adapting existing EELV technologies offers a more cost effective, solution than recreating the Space Shuttle avionics.

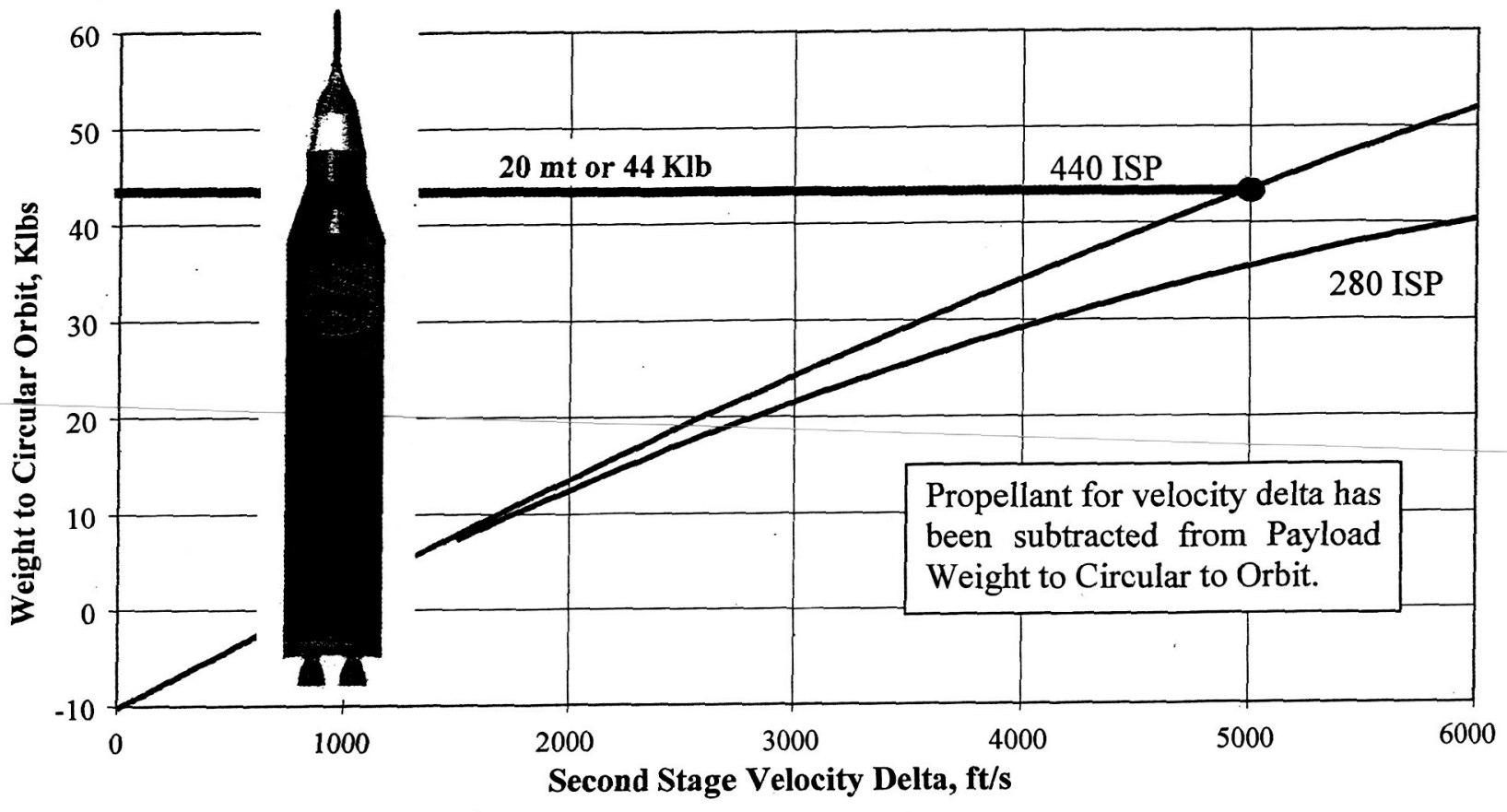

Figure 4. Weight to Circular Orbit vs. Second Stage Velocity Delta

\section{B. Heavy Lift Launch vehicle for Lunar Cargo Missions}

The intermediate lift vehicle starts with the same core stage in the CEV Launch vehicle. The intertank reverts to the ET configuration, adding back the thrust panels and SRB beam to accommodate a pair of Space Shuttle SRB's. The vehicle is topped off with a payload interface and fairing sized to provide a clear payload envelope of $6.5 \mathrm{~m}$ diameter by $25 \mathrm{~m}$ long. The baseline SRB's are the 5 segment SRB's originally proposed for Space Shuttle Upgrades. These boosters add an extra segment and change the binder from polyacrilanitrile (PAN) to hydroxylterminated polybutadine (HTPB). The comparison of the 5 segment solid rocket motor compared to the standard 4 segment Space Shuttle solid rocket motor is shown in Figure 5. The standard SRB is an option, with a likely reduction in performance of about $8 \mathrm{mt}$. The in-line configuration is capable of placing $78 \mathrm{mT}$ into a $220 \mathrm{~nm} 28$ degree inclination low earth orbit.

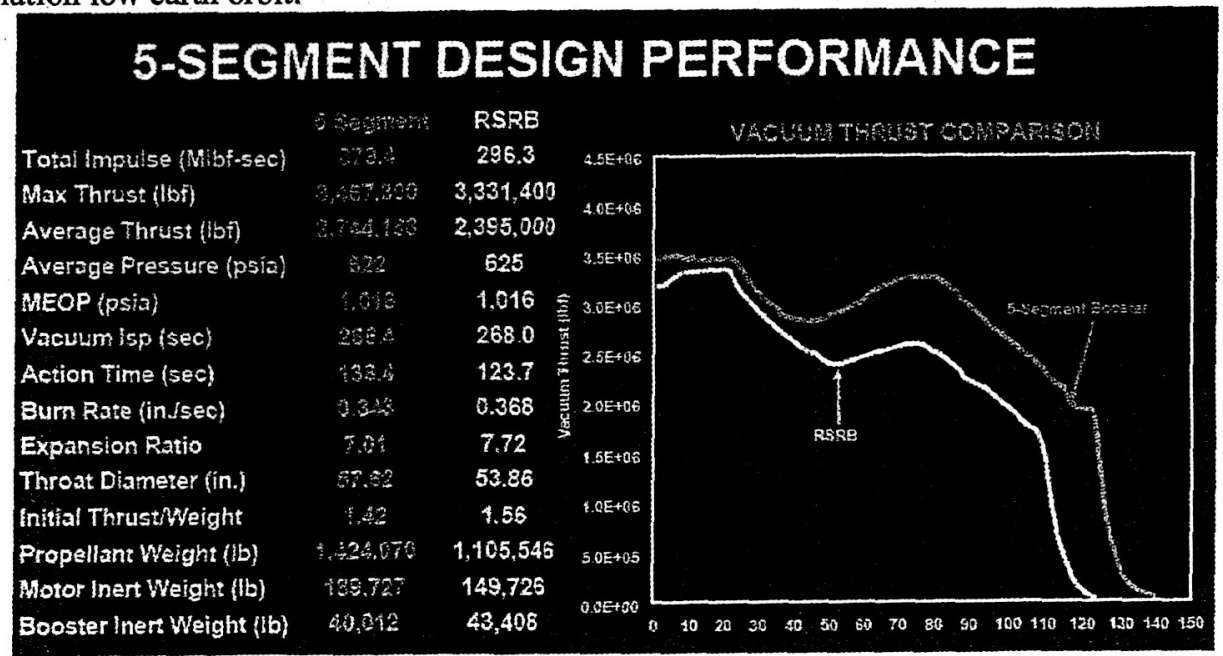

Figure 5. Performance of the 5 Segment Solid Rocket Motor 


\section{Ultra-Heavy Lift Launch Vehicle for Mars Missions}

The heavy lift vehicle is created with the addition of a large, LOX/Hydrogen upper stage and an expanded fairing. The baseline upper stage (see Figure 6) uses $245000 \mathrm{lbs}$ of propellant in tanks the diameter of the basic ET. It's powered by a single J-2S engine, a derivative of the second and third stage engine that powered the Saturn V.

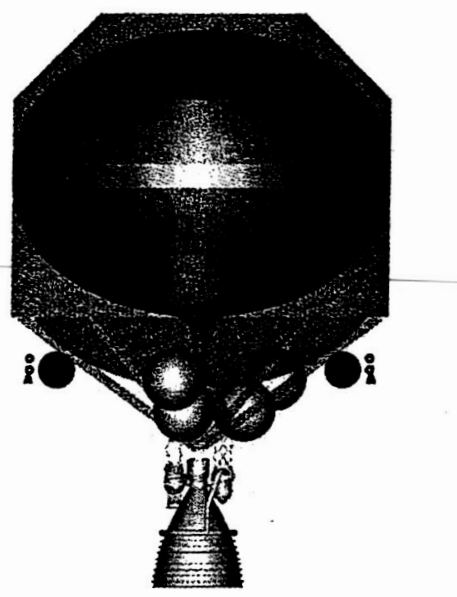

\section{Upper Stage Configuration}

- Propellant Tanks: Structurally stable aluminum orthogrid w/ common bulkhead

- Aluminum Thrust Structure

- J2S

- Storable RCS

- Ambient He pressurization

- Redundant Avionics

- Passive Avionics Cooling

- External Propellant Tank Insulation

- Insulate LO2 Tank

Figure 6. Upper Stage for the Ultra-Heavy Lift Launch vehicle for Mars Missions

The fairing is sized to provide a clear payload envelope of $9 \mathrm{~m}$ diameter by $35 \mathrm{~m}$ long. Vehicle configuration and performance is shown in Figure 7.

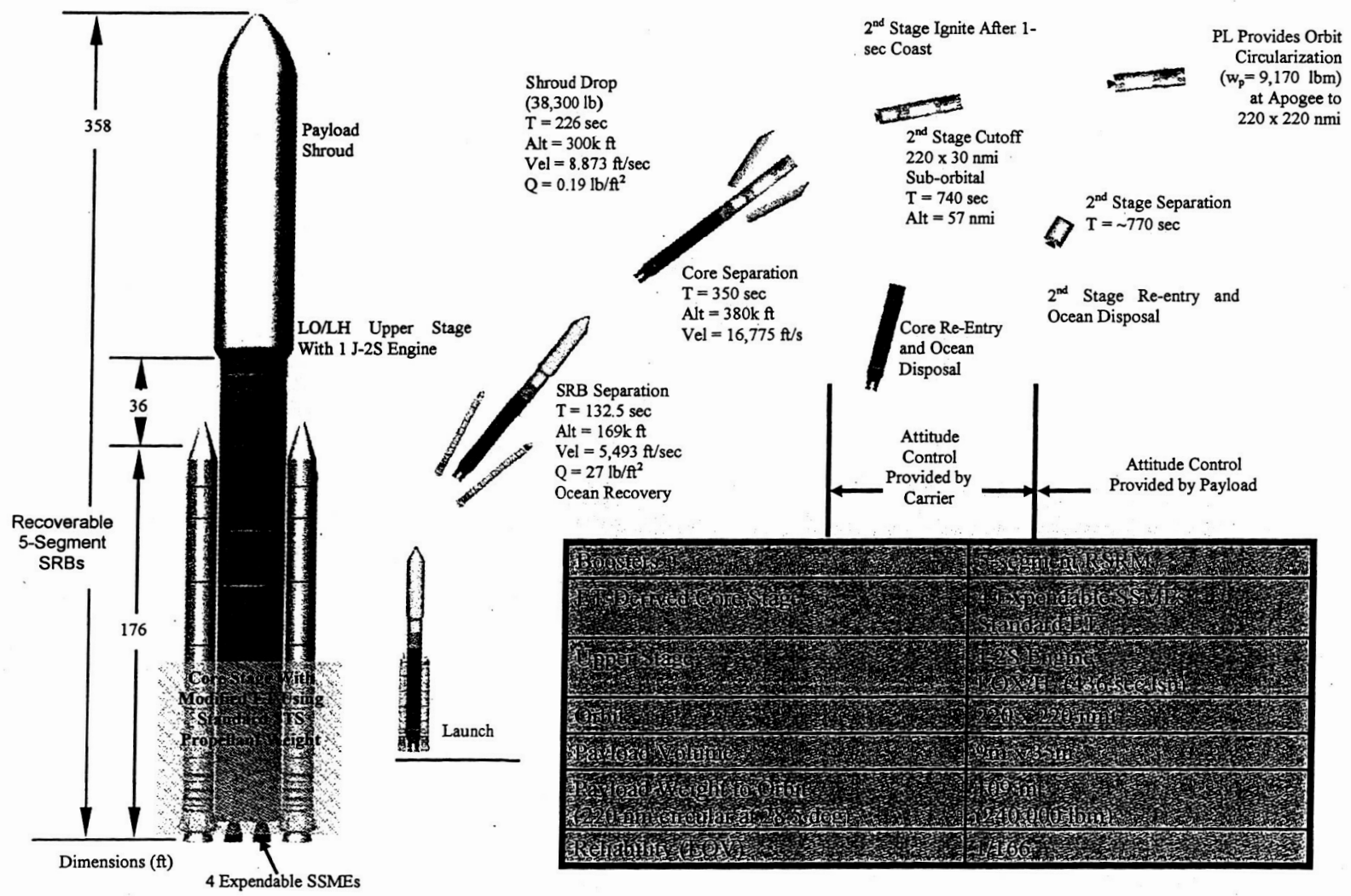

Figure 7. Earth to Orbit Mission Profile for the Ultra-Heavy Lift Launch Vehicle 6 


\section{Cost Impacts along the Evolutionary Path}

The challenges of developing a new manned space vehicle and returning to the moon are not technical, they are financial. We have done this all before but can we do it without the massive budget expenditures of the 1960's. NASA has adopted a three part strategy to meet this financial challenge. The first part of this strategy is

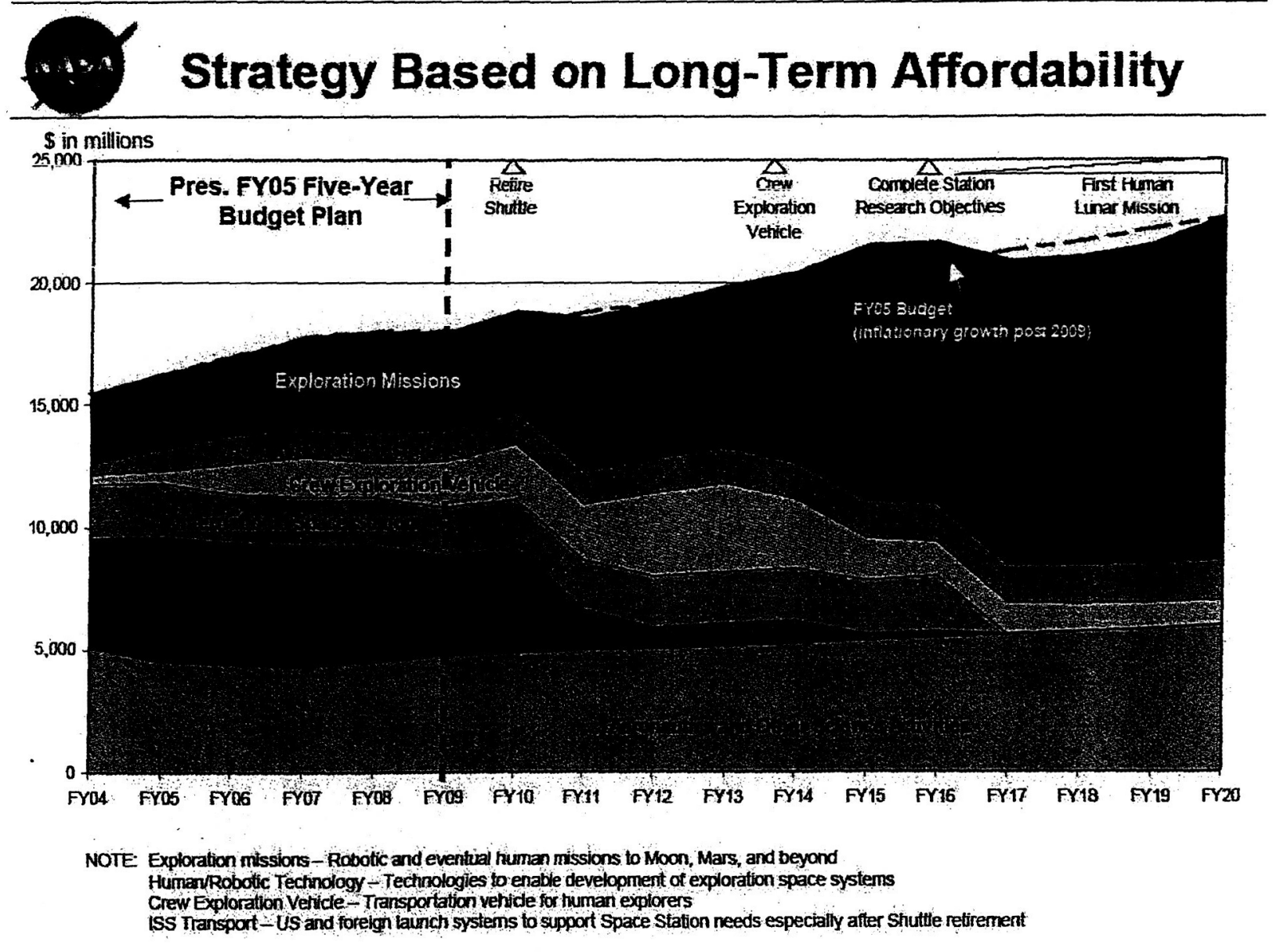

Figure 8. NASA's Financial Strategy for CEV Development and the Return to the Moon

minimal increases to the NASA budget. Figure $8^{2}$ shows these increases. Also shown in Figure 8 is the second part of the NASA strategy, the end of the Space Shuttle Program and then the end of the International Space Station program. The elements in Figure 8 that represent the Exploration program include the Crew Exploration Vehicle (CEV), Human/Robotic Technology development program and Exploration Missions. As the Space Shuttle and Space Station programs phase out, the Exploration budget increases. These two parts of the NASA strategy will create the funding required to execute the Exploration program.

The final part for the NASA financial strategy is the spiral development approach illustrated in Figure 1. When this approach is applied to the launch vehicle, an evolutionary path illustrated in Figure 2 is the result. Each vehicle along the path has its utility based on the requirements of that spiral but, at the same time, is a building block for future vehicles. The benefits of the evolutionary approach are further enhance when the use of Space Shuttle elements, components and processes are employed in the development of these vehicles. In essence, the Space Shuttle is really the first step in the evolutionary development path. 
There are three main financial effects of this evolutionary development process. The first is that the total cost of this process will be more expensive than developing the Ultra-Heavy Lift Vehicle directly by as much as twenty to thirty percent. In Figure 9, it is evident that the sum total of the cross hatched areas representing the evolutionary development cost per year is greater than the sum total of the area representing the "stand alone" development cost per year of the Ultra-Heavy Lift Vehicle. The second financial effect is that you get three vehicles for this added cost, one of which (the CEV Launch Vehicle) will be required in every spiral of the exploration program. The third

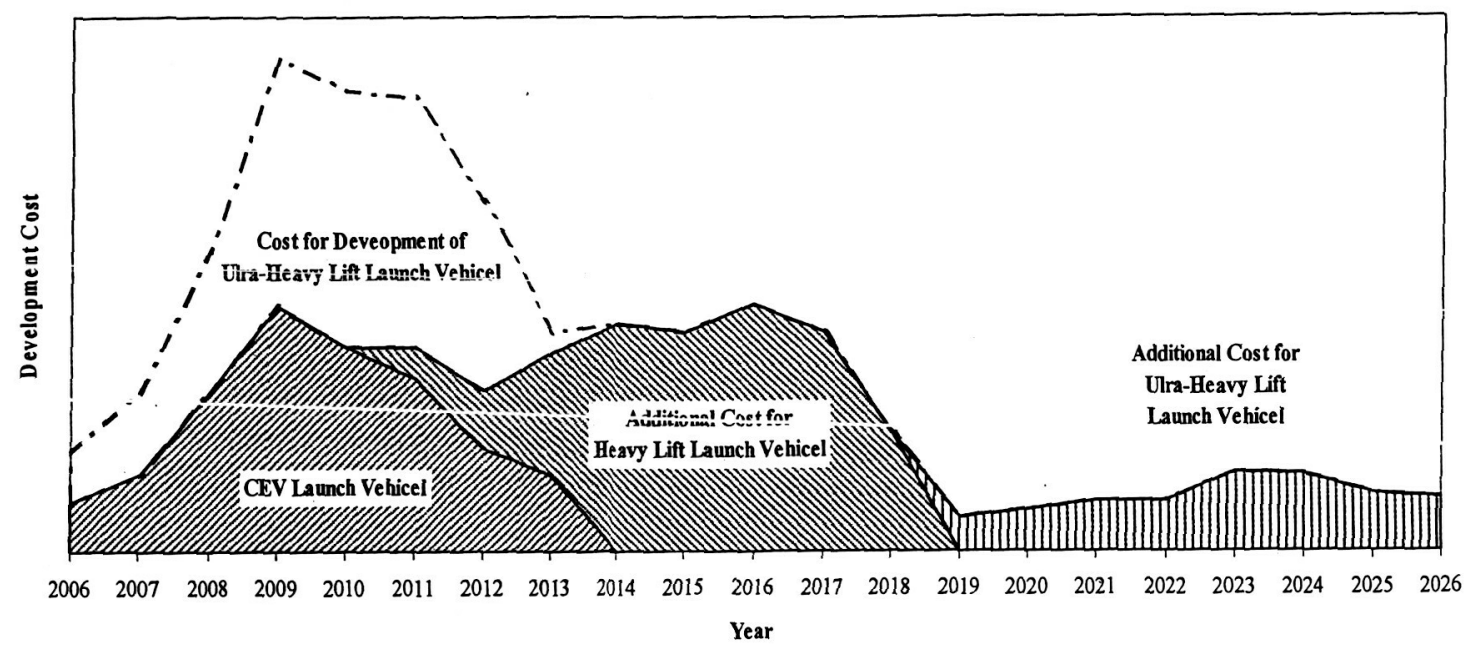

Figure 9. Evolutionary Development of the Launch Vehicles Required for Exploration yields significant reduction in yearly expenditures.

financial effect is the reduction in peak yearly development cost for the launch vehicles required to support the Exploration program. This effect is very evident in Figure 9 and persistent for eight years. This is the primary benefit of the Spiral Development approach. It greatly enhances the affordability of the Exploration program by delaying developments until they are required and building on the developments achieved in previous steps in the

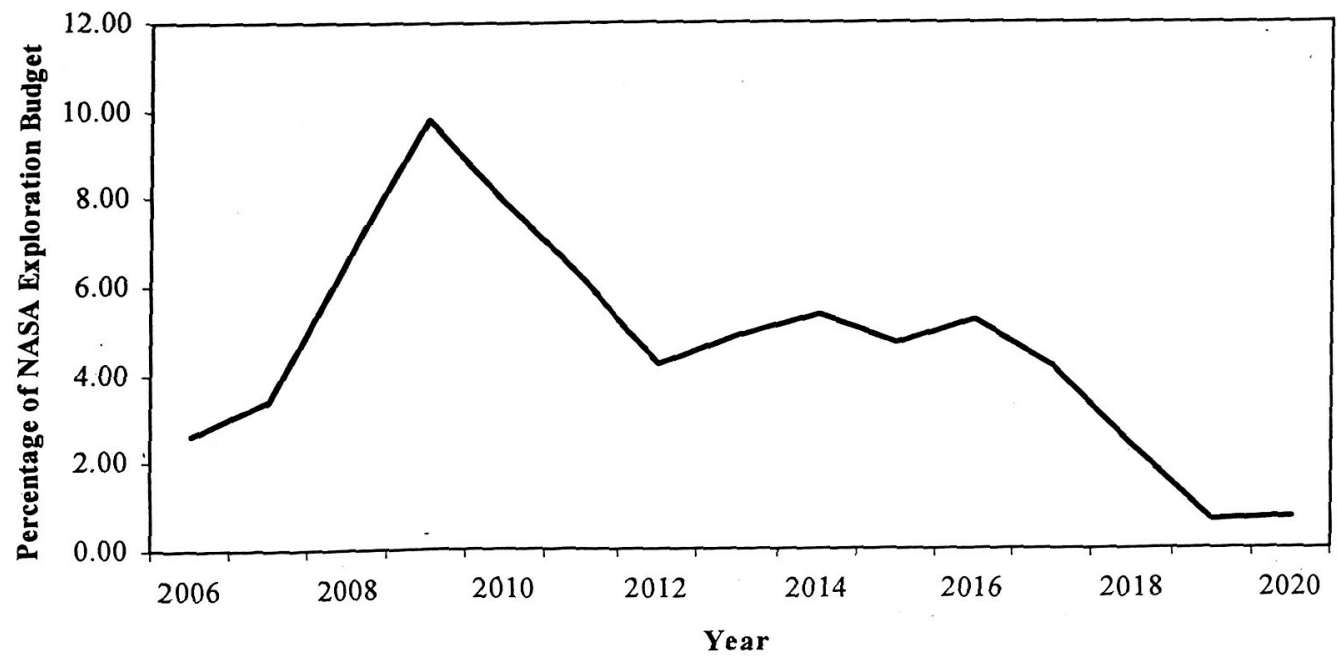

Figure 10. Launch Vehicle Evolutionary Development Costs as a percentage of NASA's
Exploration program Budget

evolution. These affordability benefits are further illustrated in Figure 10. Assuming the Exploration budget 
shown in Figure 8 (Exploration Missions, Human/Robotic Technology and CEV) and the Exploration launch vehicle development costs shown in the cross hatched areas of Figure 9, then the costs for developing the Exploration launch vehicles never exceeds ten percent of the NASA Exploration Budget and for all but a few years, never exceeds five percent. This shows that the evolutionary process allows development of the required launch vehicles without burdening NASA's exploration budget. The exploration budget can then be allocated to the more challenging tasks of developing the space craft and extraterrestrial surface craft required for the manned exploration of the solar system.

\section{Impact of Engine Selection}

This family of vehicles is designed to use liquid hydrogen and liquid oxygen propellants for the main core stage engines. The data shown assumes the use of the Space Shuttle Main Engine (SSME). Another possible main engine selection for the core stage is the RS-68 engine that is used on the Delta IV vehicle. Criteria for the engine selection include performance parameters of thrust, thrust-to-weight, and specific impulse to achieve desired payload capability; reliability; non-recurring and recurring cost; and risk. The following is a summary of each engine.

SSME - The SSME is a high performance staged-combustion rocket engine that burns liquid oxygen (LOX) and liquid hydrogen (LH2) at a mixture ratio of 6 pounds LOX for every pound of LH2. It develops a rated thrust of 470,000 pounds (vacuum) with a specific impulse of 452 seconds. Figure 11 shows the engine and its operating parameters. The engine was developed in the 1970's as a reusable engine, and it has gone through a number of upgrades and block changes to increase its reliability. The engine can be throttled from 67 to 109 percent of rated power. The current configuration is designated as Block II, and it has been operational since its first flight on STS104 in 2001. The SSME is attractive because it is fully certified for human-rated flight, and because residual engine assets would be available for use after retirement of the Space Shuttle. Both Phase II components and Block II engines and components are acceptable for use for a cargo application. Approximately 14 Block II development and flight engines are expected to be available at the conclusion of the Shuttle program, and approximately 18 sets of Phase II engine assets (2-duct Powerhead, high pressure turbo pumps, and standard throat main combustion chamber) are also available. The Phase II assets are not complete engines because the low pressure turbo pumps, ducts, nozzles, valves and lines were essentially unchanged for use with the Block II engine.

Because reusability requirement is not applicable, it provides an opportunity to make some design and processing changes to reduce costs. One necessary change is to design a new controller because many of the components in the current controller are obsolete. There is an opportunity to both simplify the construction and to take advantage of the advances in electronics. One option being considered is to develop one electronic box with redundant power supply and separate computer cards for each of the engines. Simplified input-output boxes may be used on the engines to minimize the cabling for the instrumentation. Other candidate changes to reduce cost and improve processing cycle time are to: a) eliminate items required for reuse such as protective coatings for hydrogen environment embrittlement, b) replace flex joints with flex hoses, c) switch to brazed main combustion chamber construction versus electroplated, d) use channel wall nozzle versus tube nozzle, e) replace hot-gas-manifold forgings with castings, and f) use brazed versus inertia welded injector posts. Each of these candidate changes requires further definition and study and consideration for the development and certification costs. Unit cost reductions are estimated to be to 25 percent.

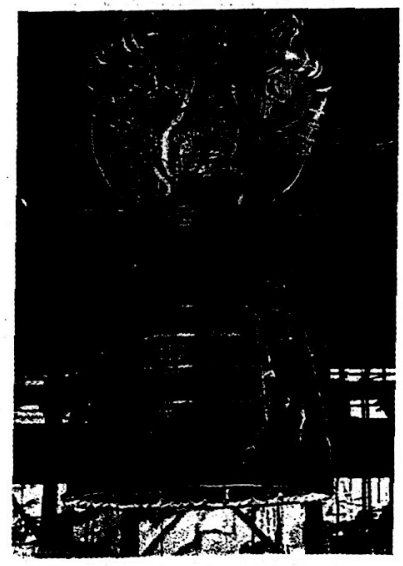

$\begin{array}{ll}\begin{array}{l}\text { Cycle } \\ \text { Propellants }\end{array} & \begin{array}{l}\text { Staged Combustion } \\ \text { Thrust, vac (lbs) }\end{array} \\ \quad \text { LO2/LH2 } \\ \quad 109 \% & 512,271 \\ \quad 104.5 \% & 490.847 \\ \text { Isp, v (sec) } & 452 \\ \text { Pc @ 109\% (psia) } & 2,994 \\ \text { Mixture Ratio } & 6.0 \\ \text { Area Ratio } & 69 \\ \text { Weight (lbm) } & 7,748 \\ \text { Throttle Range (\%) } & 67-109 \\ \text { Reliability } & 0.9992 \\ \text { Length (in) } & 168 \\ \text { Dia. (in) } & 96\end{array}$

Figure 11. Space ShuttlegMain Engine (SSME)

American Institute of Aeronautics and Astronautics 
RS-68 - The RS-68 engine is a gas-generator cycle engine that also burns LOX and LH2 at a mixture ratio of 6:1. It develops a thrust of 758,000 pounds (vacuum) and specific impulse of 409 seconds. Figure 12 shows the engine and its operating parameters. The RS-68 is the first commercially developed booster rocket engine in the world. It was developed in the late 1990's for the Delta IV vehicle which first flew in 2002. Using new design tools, simplified engine cycle, mature technologies, margin to experience, and a rich history in the development and operation of LOX-LH2 engines, Rocketdyne was able to design, develop and certify the RS-68 for approximately half the historical cost for new engine development. Because of its robust design with minimal part count, the RS68 has excellent reliability. A number of proposed upgrades (regenerative cooled nozzle, injector modifications and turbo pump upgrades) have been evaluated that increase the specific impulse and thrust. Additionally, a new controller is planned to provide health management and engine-out control capability.

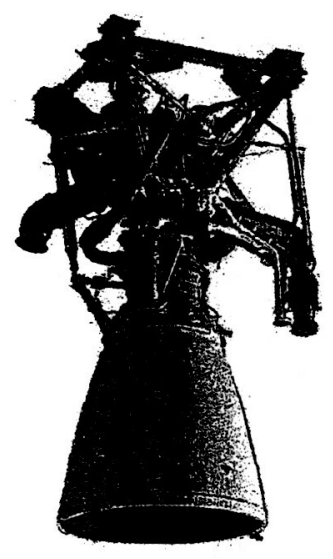

\begin{tabular}{|c|c|}
\hline \multirow{2}{*}{\multicolumn{2}{|c|}{$\begin{array}{lc}\text { Cycle } & \text { GG } \\
\text { Propellants } & \text { LO2/LH2 }\end{array}$}} \\
\hline & \\
\hline Thrust, v/sl (lbs) & 758 / $663 \mathrm{k}$ (FPL) \\
\hline Isp, v/sl (sec) & $409 / 357$ \\
\hline Pc (psia) & 1,450 \\
\hline Mixture Ratio & \\
\hline Area Ratio & 21.5 \\
\hline Weight (lbm) & 15,000 \\
\hline Throttle & $57 / 102 \%$ (MPL/FPL) \\
\hline Reliability & 0.9987 \\
\hline Design Starts & 30 \\
\hline Design Seconds & 3,000 \\
\hline Length (in) & 208 \\
\hline Exit Dia. (in) & \\
\hline
\end{tabular}

Figure 12. RS-68 Engine

The advantages of the RS-68 include higher thrust, low unit cost, short engine build cycle, and being in full production. Its disadvantages are higher engine mass and lower specific impulse. Additional study is necessary to determine whether the current RS-68 configuration is acceptable or whether some of the proposed upgrades would be required.

The selection of the engine also impacts the gross lift off weight and size of the core stage. Because of the lower isp of the RS-68 and the higher weight of the engine, the amount of propellant required to achieve the same performance of the core stage using SSME's increase between 30 and 40 percent. This results in a taller vehicle. This increase in height will impact facilities at the manufacturing site (the NASA's Michoud Assembly Facility (MAF)), Kennedy Space Center's (KSC) Vertical Assembly Building and possibly the barges used to ship the vehicle from the manufacturing site to the launch site.

\section{The Next Steps}

Several actions are required to verify these preliminary results. Initial analysis indicates that the CEV Launch Vehicle can Abort to Orbit with an "engine out" failure providing that failure occurs 1 to 2 minutes after lift off. Further analysis of the integrated abort capabilities of the launch vehicle and the CEV are required to determine if this provides the level of crew safety required. The upper stage for the CEV Launch Vehicle needs further definition to validate cost data. Since the mass properties of the Core Stage and upper stage are critical to the determining the feasibility of this concept, a more rigorous mass properties assessment is recommended. This would involve more in depth updates to structural sizing of the core stage, upper stage propellant requirements and main propulsion system sizing.

Since the primary goal of an Evolutionary development program is to spread the development cost out to méet an evolving set of requirements, the cost profile of our concept should be refined and validated by a more detail "bottoms up" analysis. More detail in the avionics and software upgrades from step to step in the evolution is required to verify costs of these upgrades. Sensitivity analyses to show the effects of variations in requirements evolution are recommended. 
The task with the most impact on this concept of evolving a family of vehicles is the choice of the core stage main engine. The RS-68 has two advantages that have yet to be explored in sufficient detail, especially as it concerns the CEV Launch Vehicle. The first is the additional thrust. This could significantly enhance the performance of the CEV Launch Vehicle and possibly afford a successful launch to orbit with an "engine out" failure immediately after lift off. The second advantage is the significantly lower cost of the RS-68. These cost savings have been preliminarily studied for the Ultra-Heavy Lift Vehicle and the results are encouraging. The primary benefit is the lower recurring costs of the RS-68. The cost of a single SSME approaches the cost of all the RS-68 engines require for an entire vehicle ship set. However, preliminary design studies on the Ultra-Heavy Lift Vehicle have shown that the use of RS-68 engines also have adverse impacts due to the increase size of the vehicle. These issues need to be examined for both the CEV Launch Vehicle and the Heavy Lift Launch Vehicle.

In addition to vehicle considerations, more detail is required in ground and launch operations to validate cost assumptions. With a large vehicle such as the Ultra-Heavy Lift Vehicle, trade studies are needed to determine the most cost effective facility support. These include such things as: a new launch pad vs. modified existing Space Shuttle launch pad, new mobile launch platforms and crawler transporters vs. modified existing ones, level of payload processing at launch site and the level of vehicle checkout required at launch site

\section{Conclusion}

The process of evolving a family of launch vehicles to support NASA's exploration program has significant benefits for meeting the primary challenge of that program. That is, developing an affordable capability to send men back to the moon and eventually to MARS. Developing this family based on the components and processes currently used in the Space Shuttle Program is technically feasible and provides additional cost benefits. The analysis results presented are sufficiently positive that more detailed feasibility analyses are warranted. Significant findings include:

1) A Spiral or Evolutionary Path has been defined which provides the Earth to Orbit launch requirements needed to launch manned exploratory missions to the moon and Mars.

2) These vehicles can be developed by using Space Shuttle and/or other existing systems, components and processes.

3) This evolutionary process combined with use of existing systems, components and processes allows development of Earth to Orbit launch vehicles in an affordable manner well within NASA's proposed funding constraints.

\section{Acknowledgments}

Much of this data and much more have been generated by a team made up of employees of the main Space Shuttle contractors, Boeing, Boeing-Rocketdyne, Lockheed Martin, USA and ATK Thiokol known as the Industry Shuttle Derived Launch Vehicle (SDLV) Team. This team's work was funded by the individual members' discretionary funds. They have worked over the last year to produce data on Space Shuttle Derived Vehicles which could support NASA's Exploration program. The Industry SDLV has brought together subject matter experts from each company in the areas of engineering, program management, operations and cost estimating. The trade studies performed have produced data that includes concept design and definition, reliability estimates, concepts of operations, costs and schedules. The team leads from each company are: Bill Rothschild, Boeing (also the Industry SDLV Team lead); Fritz Kuck, Boeing-Rocketdyne (one of this paper's authors); Bob Atkins, Lockheed Martin; Jeff Siders, USA; and, last but certainly not least, Don Sauvageau, ATK Thiokol.

\section{References}

${ }^{1}$ Nehman, J., "Exploration 'Systems of Systems' Spiral Development Discussion Panel \#2," ALAA $1^{\text {st }}$ Space Exploration Conference, Orlando FL. Jan. 30 - Feb. 1, 2005, URL:

http://www.exploration.nasa.gov/documents/reports/orlando _1-2005/discussionPanel2.pdf [cited 26 March 2006].

${ }^{2}$ O'Keefe, S., "NASA FY 2005 Budget," Congressional Budget Hearings, Washington, DC. Feb. 3, 2004, URL: http://www.nasa.gov/pdf/55522main_FY05_Budget_Briefing020304.pdf [cited 26 March 2006]. 